\title{
Correction to: A Water Quality Binning Method to Infer Phytoplankton Community Structure and Function
}

\section{Claire Buchanan ${ }^{1}$}

Published online: 20 June 2020

(C) Coastal and Estuarine Research Federation 2020

Correction to: Estuaries and Coasts (2020) 43:661-679 https://doi.org/10.1007/s12237-020-00714-3
In the original article there is an error in Fig. 5. The error does not affect any results, discussion, or conclusions in the paper. Following is the corrected figure:

The online version of the original article can be found at https://doi.org/ 10.1007/s12237-020-00714-3

\footnotetext{
Claire Buchanan

cbuchan@icprb.org

1 Interstate Commission on the Potomac River Basin, 30 West Gude Drive, Suite 450, Rockville, MD 20850, USA
} 


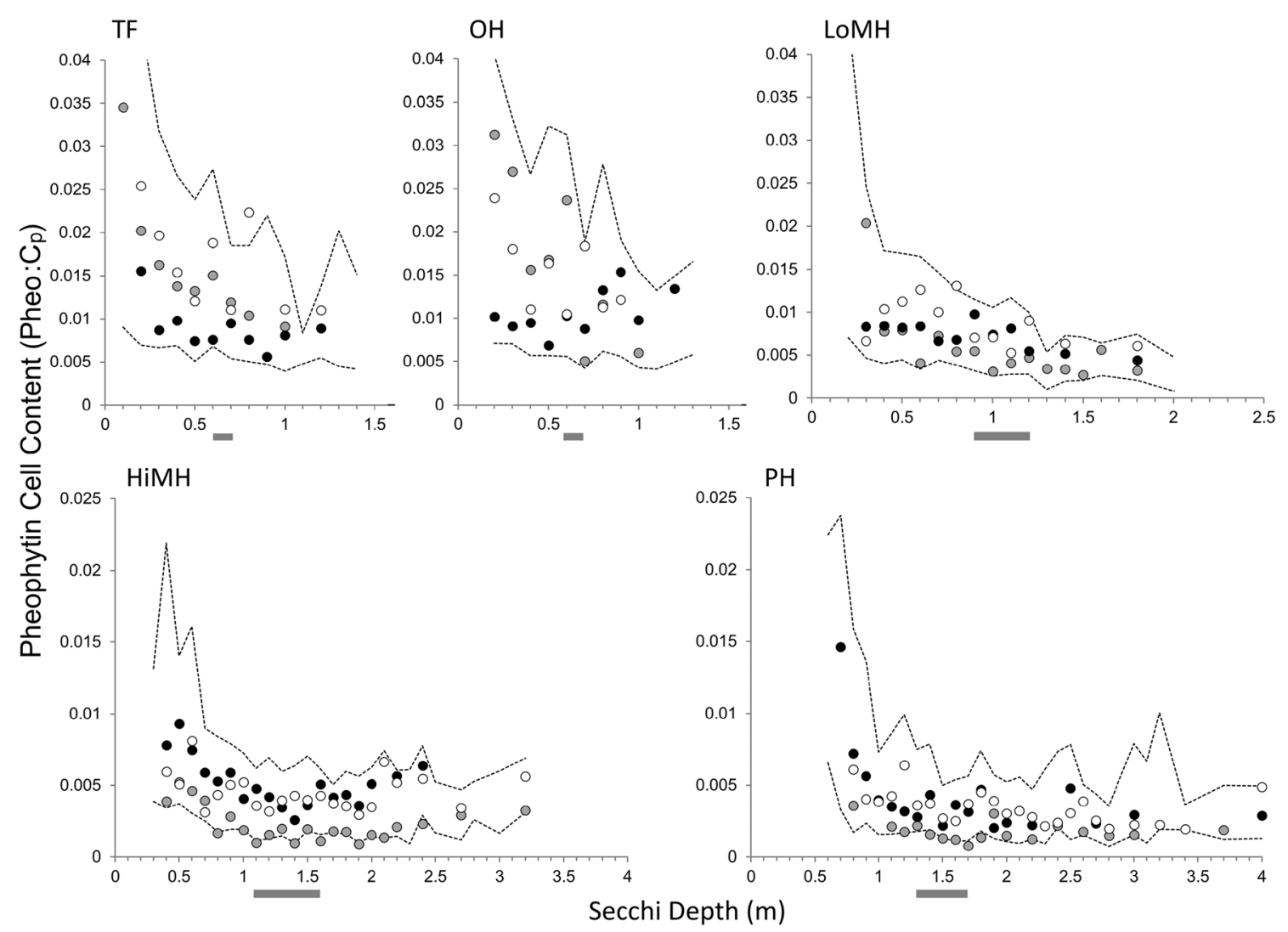

Fig. 5 The ratio of pheophytin ( $\mu \mathrm{g}^{-1}$ ) to nano-micro-phytoplankton biomass $\left(\mu \mathrm{g} \mathrm{C}^{-1}\right)$, or Pheo: $\mathrm{C}_{\mathrm{p}}$, versus Secchi depth. Gray bar, range of Secchi depth thresholds separating the worst and poor classes. See Fig. 4 heading for details 